\title{
Transition Services for High School Students with Disabilities: Perspectives of Special Education Teachers
}

\author{
Youn-Young Park \\ University of Manitoba
}

\begin{abstract}
This qualitative study examines the perspectives of special education/resource teachers in Winnipeg on current transition services to prepare high school students with disabilities for adulthood. The data were collected by individual indepth interviews with 6 teachers responsible for coordinating transition services. The main themes emerging from these interviews were the roles of schools and teachers; extended period of high school; student and family involvement; functional and comprehensive instruction; inclusive placements and experiences; and inter-personnel and interagency collaboration in the transition process in Manitoba. Interviewees identified barriers to effective transition services including limited supports and information for families, teachers, and government workers for transition services; lack of agreement concerning certain roles; delayed adult services; and lack of systematic approaches for student involvement and inclusive placement.
\end{abstract}

Over the past few decades, the inclusion of individuals with disabilities into the community and general education has been accelerated. In the early 1970s, the concepts of normalization and mainstreaming emerged in North America and brought many changes to people with disabilities (Knoll \& Wheeler, 2005). An increasing number of people with disabilities have been deinstitutionalized and live and work in the community. Along with these changes, the main concern of educators for students with disabilities has become preparing them for community living in adulthood. This qualitative study examines the perspectives of special education/resource teachers from six high schools in Winnipeg, Manitoba, on the transition services currently available for students with disabilities.

There is ample evidence that the past 25 years of mandatory public education have not successfully prepared youth with disabilities for their adult life in the community (Greene \& Kochhar-Bryant, 2003). Many students with disabilities experience difficulties in the transition process from school to adult life (Anderson \& Asselin, 1996; Freeze, 1996). According to the 
National Council on Disability (2000), for example, while the employment rate of the general labour force-between age 18 and 64 - is about $83 \%$, only $52 \%$ of those with disabilities are employed. For students with intellectual disabilities, transition from school to employment has been more challenging: $65 \%$ of adults with intellectual disabilities are either unemployed or outside of the labour force (Canadian Association for Community Living, 2006). Freeze (1996) argued that many students with disabilities in Canada are at risk of unemployment, social maladaptation, and low self-esteem in their adulthood.

Successful community life can be achieved by the positive balance of various aspects of life, such as employment, social relationships, leisure, and housing. Hence, transition, as the method of preparing students with disabilities to move successfully from secondary education to adulthood, should be a holistic and comprehensive process in order to address students' needs in various essential life aspects (Greene \& Kochhar-Bryant, 2003; Kochhar, West, \& Taymans, 2000). The Individuals with Disabilities Education Act of 2004 (SEC. 602) of the United States defines transition services as

\begin{abstract}
A coordinated set of activities that promotes movement from school to post-school activities, including post-secondary education, vocational training, integrated employment (including supported employment), continuing and adult education, adult services, independent living, or community participation and that includes instruction, related services, community experiences, the development of employment and other post-school adult living objectives, and, when appropriate, acquisition of daily living skills and functional vocational evaluation. (Office of Special Education Programs, U.S. Department of Education, 2008)
\end{abstract}

Many researchers have stressed the significance of secondary education for the transition process of students with disabilities as a means to improve their postsecondary conditions (Brolin \& Loyd, 2004; Greene \& Kochhar-Bryant, 2003). Anderson and Asselin (1996) also argued that secondary schools should take the initial responsibility for preparing students for adult life. Similarly, Freeze (1996) recommended that secondary education in Canada provide students with disabilities with more effective transition services.

\title{
Best Practices of Transition Services
}

Roessler (1990) emphasized that it is critical to identify the best practices in transition in order to provide effective and successful services. Best practices in transition refer to "a number of specific recommendations derived from empirical and non-empirical resources for facilitating successful movement from school to adult life for youth with disabilities" (Greene \& KochharBryant, 2003, p.155). Greene and Kochhar-Bryant reviewed literature on best practices of transition services for students with disabilities and identified the most frequently cited variables. These best practices are categorized into four groups: (a) student and family involvement, (b) functional and comprehensive instruction, (c) inclusive placements and experiences, and (d) inter-personnel and interagency collaboration. Each group of best practices is briefly discussed below.

Student and family involvement. In order to reflect students' needs, interests, and capabilities in the transition process, student and family involvement is essential. Many studies suggest, however, that students and families often remain passive members of the transition team 
and are not well aware of the transition process and services (Gallivan-Fenlon, 1994; Greene \& Kochhar-Bryant, 2003).

Research shows a strong connection between self-determination of students with disabilities and successful transition outcomes (Wehmeyer \& Palmer, 2003). In addition, in order to empower students with disabilities to make decisions about their own lives, the development of selfdetermination and advocacy should be included as part of the transition process (Council for Exceptional Children, 2000; Greene \& Kochhar-Bryant, 2003; Stuart \& Smith, 2002).

Families can play critical roles in supporting students with disabilities and their involvement is essential for transition planning. In fact, Morningstar, Turnbull, and Turnbull (1995) showed that youth with disabilities whose families were actively involved in transition planning achieved better employment-related outcomes after graduation than those without strong family involvement. Family is the continuous advocate, informant, and supporter for students with disabilities (Brolin \& Loyd, 2004).

Functional and comprehensive instruction. For students with limited functional skills, functional and comprehensive approaches to preparing them for adult life are essential. Functional skills are those that have a high probability of being used by students in their future placements in educational, vocational, residential, and community environments (Johnson \& Wehman, 2001). The suggested functional and comprehensive goals of the transition process in school include the following: career/vocational development; social development; independent living, recreation and leisure; emotional/physical health; personal responsibility/relationships; and community involvement (Greene \& Kochhar-Bryant, 2003). Researchers also stress that functional instruction for students with disabilities should be combined with community-based experiences (Greene \& Kochhar-Bryant, 2003; Kamens, Dolyniuk, \& Dinardo, 2003). For students who have difficulties generalizing their learned skills from classroom to real-life situations, functional instructions need to be provided in environments where those skills are likely to be used (Greene, 2003a; Wehman, 2001).

Inclusive placement and experiences. It is unreasonable to expect students with disabilities to transition successfully to adult life in the community without inclusive experiences during their adolescent years (Greene, 2003a). Research has shown that youth with disabilities who have had inclusive experiences in their school and community achieved better postsecondary outcomes in areas such as social relationships and employment (Council for Exceptional Children, 2000; Greene, 2003b; Luecking \& Certo, 2002). Education and experiences in inclusive environments with peers provide typical and age-appropriate role models for students with disabilities (Greene, 2003a). Greene (2003b) noted, however, that although inclusive educational opportunities for students with mild disabilities have significantly increased, many students with moderate or severe disabilities are still educated for most of their school life in segregated programs with little contact with peers without disabilities.

Inter-personnel and interagency collaboration. When transition services require the involvement of a variety of professionals from many disciplines, their collaboration-interpersonnel and interagency_is essential (Greene \& Kochhar-Bryant, 2003). It is therefore critical that professionals understand the transition process and services for students with disabilities and each other's roles and responsibilities in the process (Greene \& Kochhar-Bryant, 2003). To develop channels of communication and iron out policy differences, researchers have suggested the 
development of school-interagency transition teams (Phelps \& Maddy-Bernstein, 1992). Furthermore, Greene and Kochhar-Bryant (2003) suggested that the interagency team should aim to (a) facilitate interagency linkages, (b) improve the ability of systems to respond to changing needs of students, and (c) reduce fragmentation of local services. In addition, interagency agreements, which include specification of the activities, responsibilities, and financial contributions of each agency, are an effective tool for such teams to promote communication and to share information, resources, and services.

\section{Contextual Background in Manitoba}

Since 1989, Transition Planning Process - an inter-departmental protocol-has mandated individualized transition planning for students with disabilities in Manitoba, at 16 years of age or older, who require ongoing adult services (Manitoba Education, Youth, and Citizenship, 1989). Manitoba schools are required to initiate transition planning meetings to collaborate with other community service providers and to either infuse transition planning in the Individual Education Plan (IEP) or develop a separate Individual Transition Plan (ITP) for applicable students.

\section{Current Practice in Transition}

Despite a mounting body of research on transition conducted mostly in the United States, very little research - either empirical or theoretical — has been conducted in Canada in this critical area. The limited Canadian research on transition presents a sketchy but concerning picture of current transition practice for students with disabilities in Canada. Horrocks (1991) reported that many high school graduates with disabilities failed to obtain competitive employment or postsecondary education. In action research in Manitoba, families of students with intellectual disabilities also expressed their frustration during the transition period due to lack of information of adult services and options, fragmented and confusing service systems, and difficulties in developing realistic expectations (Mactavish et al., 2004). In addition, Freeze (1996) pointed out the limited access of students with disabilities to employment, community involvement, and postsecondary education or training after graduation.

While recent research suggests that most youth with disabilities and their families experience difficulties in transitioning to adulthood in the community, there has been very little empirical research on how Canadian secondary schools and support systems prepare students with disabilities for adulthood. Examining current transition services and identifying barriers may improve the current support system to better assist students and families for transition. Because special education teachers in Manitoba are expected to be actively involved in the whole transition process for individual students and play a critical role in determining the direction and effectiveness of transition planning, this research focused on examining their perspectives on current practices.

\section{Method}

This study was designed and conducted by the author. My academic background is special education. Because my career has been mainly devoted to supporting adults with disabilities 
for community life, such as employment, independent living, and family life, when I started this research I had not been involved in the school system and therefore was not familiar with the transition practices provided by the local schools. This research was my effort to understand the current transition practices in school settings.

\section{Participants}

Six special education teachers at high schools in Winnipeg, Manitoba-each from a different school division - participated in this research. They were recruited either by indirect personal contacts or recommendations from the directors of Student Services of the school divisions. The criterion for participation was being a high school special education teacher with responsibility for transition services for students with disabilities.

The participants were from integrated schools, not special schools, which were located in an urban area and had student populations from 700 to 1,250. The participants included 4 female teachers and 2 male teachers. Their experience with transition services in secondary education for students with disabilities varied from 1-7 years. Individual participants' roles and the degree of the disabilities of the students under their charge are presented in Table 1. The names of the participants are pseudonyms. The degree of support needs of the students of the participants in Table 1 is based on their eligible funding categories in Manitoba (e.g. Level I, II, and III for mild, moderate, and severe needs, respectively, for a major part of the school day). The participants' students had various disabilities, such as mental disabilities, physical disabilities, learning disabilities, emotional/behavioural disorders, psychosis, Autism Spectrum Disorder, hearing impairment, visual impairment, and multi-disabilities, because these are the eligibility conditions for Manitoba funding Level I, II, and III (Manitoba Education, Youth, and Citizenship, n.d.).

\section{Data Collection}

The data were collected from the participants using in-depth, semi-structured interviews. Because this study aimed to obtain detailed and descriptive data of the current practices of transition services and teachers' perspectives on it, individual interviews were considered the most appropriate means for data collection. Interviews with students and families to balance teachers' perspectives were beyond the scope of this study.

Each teacher was interviewed once in person. On the day of the interview, before beginning the interview, I briefed each teacher about the research project and asked them to complete a consent form. I tape-recorded all interviews and took field notes on participants' body language, attitude, and emotional conditions during and immediately after the interviews. The interviews took place in the school offices of the teachers by their preference. The interviews took place during school hours and took from 50 to 80 minutes to complete. The interviews were conducted with open-ended questions on the practice of transition in their schools, including the transition process and supports, student and family involvement, and inter-personnel and interagency collaboration. Specific interview questions are presented in the Appendix. 
Table 1

Participants' Roles and the Degree of Support Needs of Their Students

\begin{tabular}{|c|c|c|}
\hline Participant & Student needs & Major role \\
\hline Ann & Mild to severe & Coordinating transition services ${ }^{a}$ and educational programs ${ }^{b}$ \\
\hline \multirow[t]{2}{*}{ Bob } & Moderate to severe & Coordinating transition services and educational programs \\
\hline & & Teaching $^{c}$ \\
\hline Cathy & Mild to moderate & Coordinating transition services \\
\hline \multirow[t]{2}{*}{ Dan } & Moderate to severe & Coordinating transition services and educational programs \\
\hline & & Teaching \\
\hline Ella & Moderate to severe & Coordinating transition services and educational programs \\
\hline Fin & Mild to severe & Coordinating transition services and educational programs \\
\hline
\end{tabular}

${ }^{\mathrm{a}}$ Coordinating transition services include individualized transition planning, working with government and community service providers (both for children and for adults), arranging work experience, and collecting information on adult services. ${ }^{\mathrm{b}}$ Coordinating educational programs include scheduling, conducting assessments, developing IEP and curricula, working with specialists and paraprofessionals, and holding IEP meetings. ${ }^{\mathrm{c}}$ Teaching includes both classroom and/or individual student teaching.

\section{Data Analysis}

The data sources were the interview transcripts, field notes, and my interpretive notes from the interview and transcription process (inserted in the transcripts). I used the constant comparative method according to the six steps delineated by Glaser (Bogdan \& Biklen, 1998; Glaser, 1978). When conducting several interviews in sequence, I transcribed the interviews and marked noteworthy statements with preliminary codes describing key concepts. The preliminary codes were conceptualized in terms of roles and responsibilities; curricula and programs; transition planning process; and the participants' observations and experiences, emotions, and perceptions (e.g., assumptions, suggestions, and barriers). At this early stage of the coding process, some key topics emerged, such as the roles of teachers, inclusive placements, and work experiences. I included the key topics identified from earlier interviews in the questions for subsequent interviews. In addition, I continued to reexamine the transcripts, refining the coding and identifying supporting details or any possible contradictory information. After completing the data collection, I reviewed the data to refine the coding further and to identify common, broad topics, such as student and family involvement and inter-personnel and interagency collaboration, which were components of the planned interview questions, as well as inclusive experiences and career development that emerged as key topics during the interviews. I assembled coded statements into common topics by copying and pasting in word processing files. Then the data in each topic file were examined to identify specific themes. The original transcripts were reviewed once more to confirm the themes identified and to locate any missing data related to the themes. The results of this analysis are discussed by these themes below. 


\section{Results}

Common themes emerged from the interviews: roles of schools and teachers; extended period of high school; student and family involvement; functional and comprehensive instruction; inclusive placements and experiences; and inter-personnel and interagency collaboration in the transition process. Key issues identified from each theme are discussed in this section.

\section{Roles of Schools and Teachers}

All the teachers in this study acknowledged the significance of secondary education in preparing students with disabilities for adulthood. However, it was apparent that in most of the schools, transition services for students with disabilities had only developed over the past few years.

The schools and the teachers appeared to play critical roles in providing transition services for students with disabilities. The duties that the teachers were involved with regarding transition for students with disabilities included (a) coordinating transition services such as networking stakeholders and arranging meetings; (b) informing students and families of the transition process and services; (c) developing the skills that students require for adult life, such as vocational, daily living, social, and personal skills, as well as arranging work experiences; and (d) supporting students and families in finding and applying for suitable adult service agencies.

All of the teachers defined their major role as that of a coordinator or manager. Their job descriptions had often changed in recent years and they were no longer confined to the typical duties of classroom teaching. Cathy stressed the necessity of flexible schedules and duties in order for teachers to be able to address transition issues for students with disabilities:

A classroom teacher who's bound to the classroom can't do that [transition planning] effectively...efficiently.... The thing with school though; teachers of these programs can be too classroom bound. They have to be freed up - out of their classrooms - to get out and go out and visit these places [adult service agencies].

\section{Extended Period of High School}

The vast majority of the students with disabilities that the teachers in this study were responsible for remained in high school until age 21 due to the Manitoba government support system for adults with disabilities. The teachers suggested that the main reason for this was that more than $80 \%$ of these students qualified for Supported Living Services - one of the government services for adults with cognitive disabilities who require intensive and on-going residential and day-program supports - which are not accessible until age 21. Furthermore, the teachers claimed that without Supported Living Services funding, there were no adult services available for these students between the age of 18 and 21 . Therefore, most of the students chose to stay in school until 21 years of age, and this extended their high schooling by about three years.

Some of the teachers noted a few advantages of this extended high school period. First, it allowed more time for the schools, students, and families to prepare for the transition. Second, some teachers could more easily facilitate the integration of their students into regular classes before age 18, knowing that they would still have some years later to prepare the students for the 
transition. Last, students with disabilities who need more than the typical four years of high school to complete their course credits also benefited from the extended period of high school.

However, the teachers also argued that sometimes the extended period of high school caused problems for the transition of students with disabilities. The most pervasive problem that the teachers perceived arose when students who were qualified for Supported Living Services wanted to graduate at 18 years of age with their peers. Cathy presented an anecdote regarding such cases:

Where family has really strongly advocated for their young person to graduate prior to $21 \ldots$ that's a difficult situation because if they're Supported Living, they're not eligible for program funding until they're 21 . So... we have to really sit down with them and ensure that they know what this means. I don't want to see a situation where a young person graduates and there is no support out there.

In addition, in some schools the program for students with disabilities after age 18 was mostly repetition of previous courses which were mainly academic-based.

\section{Student and Family Involvement}

Most of the teachers in this study reported that students with disabilities and their families were actively involved in transition planning and the process, especially in setting goals and making decisions. For instance, Dan claimed, "The best majority [of students and parents], 9095\% are fairly involved [in the transition planning process]". Cathy stated, "They [students] are part of IEP meetings, part of information sessions... part of the assessments of themselves.... They are made aware of what's going on." Fin also stated, "I don't make any plans without having the family's involvement." Emphasizing the significance of empowerment of students and families in the transition process, Bob stated,

We [school] want to hand over the responsibility to the parents and the student, and give them a clear idea of where they want to go and what partnerships they have to develop with Community Services, an employment agency.... whatever.

Unlike the other teachers, however, Cathy expressed some difficulties in involving students and families in transition planning and the process.

While reporting the high involvement of students, some teachers also pointed out one common barrier: Three teachers acknowledged that the cognitive and communicative limitation of students with disabilities often impeded their full participation in the transition process. The general approach of these teachers to this barrier is best represented by the comment, "to the extent that they [students] are capable." In addition, the teachers rely on the families of students with significant cognitive or communicative disabilities to reflect the students' interest in the transition process.

The teachers agreed that most families were supportive and collaborative in the transition process. However, they expressed some difficulties in working with some families. The challenges included impractical demands for support services for the student, unrealistic expectations for the future, denial of their child's disability, and familial lack of resources and dysfunction. Cathy pointed out parents' denial: "My child's not that special, my child doesn't need special support." According to Cathy, such cases occur frequently. In addition, Bob testified, 
Others [parents] are still living a fantasy that somehow their son or daughters are going to have a miraculous cure... they won't be mentally retarded, they won't be bound in a wheelchair, or they won't be having seizures every day.

Moreover, according to the teachers, some parents' conditions, such as overburden, stress, drug or alcohol addiction, mental illness, or their own disabilities, were also factors which restricted their involvement in the transition process.

Expressing sympathy and understanding toward the distresses that the families of students with disabilities experienced, some of the teachers noted the significance of support for the family. Bob stressed early support for the families in order to help the students and families for successful transition: "I think supports going to families have to happen earlier [than high school].... So they are not filled with fear and doubt, or are resistant to changes that they don't understand."

The teachers identified informing families about the transition process and services as one of the most challenging, but also most crucial, tasks in supporting students with disabilities and their families during the transition period. Some of the teachers admitted that many families were still not aware of the process and services. Ella noted,

I think it's [transition] a mystery to them [families] overall. I think that they feel lucky when they get service. I worry that they just take the first thing that seems to come along rather than the best fit, because they get kind of panicked, 'where my child would be...' It's just a time of unknowns.

The teachers related the difficulties of informing families about the transition process and services to three main factors: lack of family involvement, a complicated service system, and a lack of information sources. In addition, the teachers expressed difficulties in locating relevant information even for themselves. Dan said, "[I'd like to have some information on] how they get involved in Special Olympics, tax information...that kind of stuff. I haven't found a single source for that. It's kind of all over the place." Furthermore, there was some disagreement among the teachers as to who should be responsible for informing and educating the families regarding the transition process and services. Although most of the teachers appeared to spend much of their time and effort in this regard, some did not agree that it was their legitimate responsibility. For example, Fin argued,

What would be nice would be if there was one person who knew all the agencies in the city and could point out and meet with the families and teachers, find out what they want... because in my job I don't have time to do that. I don't know who would do that.

\section{Functional and Comprehensive Instruction}

The school programs that the teachers provided appeared to cover various domains of education and transition, but the focus of each domain varied between schools. The educational goals and objectives of all these teachers' schools generally included academic, vocational, social, behavioural, personal care, daily living, self-management, and leisure domains. However, there were differences in the way curricula, class timetables, and activities were arranged for students with disabilities in each of these domains. While two of the teachers stated that their curricula and instruction for students with disabilities were academic-centred in general, the other 
four claimed that their approach varied from academic-centred to functional, based on individual student's abilities and needs.

Among various transition domains, vocational development appeared to be the area that most of the teachers focused on for transition. In fact, every school in this study arranged work experiences for students with disabilities. The placements, supports for, and time devoted to work experiences, however, varied depending on individual students, from sheltered workshop to community-based worksites and from one-on-one assistance from educational assistants to training from employers or coworkers. Work experiences ranged from a few hours a week to five full days a week. Some schools also provided general vocational education on topics like career interests, work ethics, interview skills, and résumé development. While one of the schools provided students with disabilities with vocational courses as part of the curriculum of the school division, the others provided vocational instructions developed for individual students with disabilities.

Some of the teachers reported that providing instructions and experiences in the community was part of their school programs. For instance, Dan explained,

During a day some [students] would spend like a lot of this work...working on money math and using that in the real world settings, so going out on different trips to buy things in stores, and to practice making change, things like that.

The interviews with the teachers indicated, however, that community-based instructions and experiences - except work experiences - remained a limited part of school programming in most of the schools. The teachers noted that the number of outings for community-based instruction or experience ranged from as little as once a month to as much as once a week. In addition, most of the outings that the teachers described appeared appropriate to familiarize students with the community environment rather than to further develop independence or specific skills of individual students with specific objectives.

\section{Inclusive Placements and Experiences}

Most of the teachers emphasized the efforts to provide inclusive experiences for their students with disabilities in school and in community, believing in their importance in helping students prepare for community life. However, the amount of inclusive experiences that their students had during school hours varied depending on schools and on individual students' circumstances. With regard to classroom placements, for example, two teachers claimed that the vast majority of their students with disabilities attended most regular classes; three teachers reported that their students participated in both regular classes and separate courses; and one teacher stated that her students spent most of their school time in a separate program.

The teachers identified some factors that influenced the placements, whether inclusive or separated, for students with disabilities. The most frequently mentioned factors related to the student's characteristics, such as cognitive and physical ability, interests, and behavioural problems. Family's values and interests were also considered as significant factors. The teachers perceived that families had particularly strong voices on the decision about where to go for work experiences, whether a community-based business, sheltered workshop, or day program. For example, Dan discussed an example where parents made a decision about their daughter's placement: 
There is one student.... She has been going independently to work sites, hasn't even needed an educational assistant with her. She's connected well out in the community and she's just doing fantastic, like a real success story. But yet the parents, they don't see it or don't want to see it. So they want her to go to a day program, where she's not out at work, just be in a place somewhere. That's really frustrating.

The school schedule or activities, such as individual students' transportation schedule, individualized activities, and work experiences, arranged for students with disabilities was also identified as a factor that reduced the level of inclusion of students with disabilities.

\section{Inter-personnel and Interagency Collaboration}

The teachers claimed that transition services were provided through a team approach involving various school personnel and other agencies, including students and their families. The team members appeared to be diverse depending on individual student cases. The general rule was including "anybody that is involved in supporting a student," as Ella said. The school staff that the teachers worked with in providing transition services included paraprofessionals; psychologists; occupational therapists; physical therapists; language therapists; administrators; classroom teachers; teachers from other schools within the same school division; and in some schools, work experience teachers from the school or the school division. External personnel that were involved in the transition process were government social workers, adult service agencies, advocacy organizations, and local businesses. The teachers perceived their collaboration among school personnel and with the government and other agencies as positive in providing transition services for students with disabilities.

However, there were some concerns raised by the teachers in regard to working with government social workers. First, the teachers acknowledged that many social workers were overworked. Bob claimed that the school took the major responsibility in providing transition services for students with disabilities and their families, because the government workers were too overburdened. Some teachers expressed difficulties in making contact with social workers. Fin, however, pointed out that it might be because the workers were overworked. The next concern was regarding the turnover of social workers. The teachers argued that frequent turnover of the social workers often impeded consistent supports for students with disabilities in the transition process.

In addition, the teachers had different perspectives on who should be responsible for some of the transition services, that is, the respective roles of teachers and social workers. The particular roles in question were informing students and the families of the transition process and resources and finding suitable adult service agencies for the students. Although some teachers reflected that the government social workers should be in charge of those two tasks, the other teachers assumed them to be their own responsibility. However, most of the teachers took the responsibility of informing students and their families about the transition process and services, and some of them were involved in finding postsecondary placements for students. Dan's statement well represents some of the teachers' perspectives on this matter:

I don't like to leave it [finding postsecondary placements] up to them [the government workers].... It's often left to parents to go out, 'choose what you want to do, and let us know and I'll arrange the funding.' I just think that it's too big a decision to leave it like that. So that's why I try to spend 
time to narrow down to maybe six different alternatives [adult service agencies] $\ldots$ and their parents go and explore those programs.

It was not clear from the interviews in this study who really had the responsibility for these most crucial tasks - no written agreements or regulations defining the role of each partner were found. This confusion of the roles, however, apparently interfered with effective collaboration between schools and the government in providing transition services for students with disabilities.

\section{Discussion}

The results demonstrate some features of current transition practices in these schools and identify issues to be addressed. First, the transition services described by the teachers in this study were diverse in terms of inclusive placements, functional instruction, student and family involvement, and the extent of internal and interagency collaboration. It was apparent that each school had its own strengths and weaknesses in terms of transition services. It would thus be valuable for schools to share information, resources, and strategies for the development of effective transition services (National Council on Disability, 2000). My impression from the interviews, however, was that the teachers did not know much about how other school divisions, schools, and teachers perform in providing transition services for students with disabilities. Therefore, various means to facilitate communication among schools and teachers about transition services need to be developed, such as forums, conferences, information centre, on-line network, and coprojects.

Another common practice identified from the interviews was that the teachers took on many of the roles of a transition coordinator without having any official designation as such. Research has stressed the critical role of transition coordinators in providing leadership to guide the student, family, and team to accomplish meaningful transition outcomes (Baer, 2005; Flexer, Simmons, Luft, \& Baer, 2005; Greene \& Kochhar-Bryant, 2003; Stuart \& Smith, 2002). Despite the teachers' efforts as coordinators, it was apparent that there were diverse perspectives on the roles of schools and the government between the teachers and social workers, particularly in informing students and families of the transition process and services and in locating adequate adult services available for individual students. The uncertainty of their specific roles apparently interfered with the collaboration between schools and the government in delivering transition services. This confusion of roles may be caused by a lack of policy specification of specific stakeholder roles. While The Transition Planning Process (1989) - a Manitoba interdepartmental transition protocol-requires schools to be leaders in coordinating transition services, no clear definition of the roles of key players exists. Interagency agreements may be beneficial to clarify the responsibilities of all involved in providing transition services from each agency (Kochhar-Bryant, 2003b).

All the teachers in this study perceived that their students with disabilities and their families were, for the most part, actively involved in the transition planning process. This claim is particularly noteworthy in light of research which suggests a lack of student and family involvement as an obstacle to successful transition (Gallivan-Fenlon, 1994; Greene \& Kochhar-Bryant, 2003). This claim of the teachers may be interpreted either as different perceptions between teachers and students and the families or as indicating advanced practices of the schools in this study. It was apparent, however, that involving students and the families in transition planning and the process was one of the key tasks to which the teachers devoted their effort. 
From the comments of the interviewees, teachers' beliefs in inclusion and schools' prearranged placement systems may be factors that affect the placements of students with disabilities in school and community. The teachers in this study perceived that the placements of their students were decided by the individuals' and families' needs, interests, and attitudes. Nonetheless, the pattern of placements of the teachers' students was apparently largely determined by individual schools, regardless of students' disabilities. For example, despite the similar degree of support needs (moderate to severe) of their students, Dan's and Ella's students showed clearly contrasting patterns of placement. All of Dan's students participated in regular classes (more than half their courses in most cases) and in community-based work experiences, while the majority of Ella's students were educated primarily in a separate program and did work experiences in sheltered workshops or day programs. Schools and teachers need to closely examine their efforts to facilitate inclusive placements.

\section{Recommendations}

The results strongly suggest the need to improve the current support system in delivering transition services for youth with disabilities in Manitoba. The four main recommendations emerging from this study are discussed below.

First, the government needs to ensure that requisite adult services are accessible to the youth in need. The current unavailability of Supported Living Services until the age of 21 restrains the person-centered transition planning of some students by forcing them to remain in high school against their interests. This practice also defers the initiation of adult life of some students with disabilities, which is against the principles of normalization and ageappropriateness in supporting people with disabilities (Flexer \& Baer, 2005; Knoll \& Wheeler, 2005). Mactavish et al. (2004) also reported that this gap of services in Manitoba is one of the major difficulties that students with disabilities and their families experience in the process of transition. In addition, the teachers pointed out that most of the services provided for students during school years, such as one-on-one support, language speech therapy, and occupational therapy, would not be available after graduation. Without those supports, adjusting to and maintaining a successful adult life is highly improbable for many youth with disabilities. It was apparent from this study that the current adult services available in Manitoba fell far short for the majority of adults with disabilities to work and live in the community.

Second, supports for families must be better developed as part of transition services for students with disabilities. The teachers emphasized that the families needed supports to overcome their distress and to be better equipped to properly assist their child in the transition process. Gallivan-Fenlon (1994) also noted a lack of support or services for the families as a barrier to successful transition for students with disabilities. Suggested supports for families during transition include networks with community resources, information/learning centres, parent-toparent support groups, childcare, and psychological counseling (Wehman, 2001). These supports will be helpful to relieve the families' stress and concerns and to empower them, which is essential for the successful transition of their youth.

Third, the government, schools, and community services providers need to ensure that team members are properly equipped to deliver effective transition services. Kochhar-Bryant (2003a) noted that the lack of resources of team members is one of the barriers to effective interagency collaboration. The teachers testified that very little support and few resources were pro- 
vided for them to efficiently perform the role of transition coordinator, such as access to a legitimate authority to oversee the transition process, flexible timetables, financial and human resources, information, and pre- and in-service training. The government needs either to train professional transition coordinators or to provide adequate support, resources, and training for teachers to effectively coordinate transition services (Blanchett, 2001; Grigal, 2000). In addition, the teachers also pointed out the apparently excessive caseload of social workers, which could create other problems, such as frequent staff turnover and inaccessibility, as one of barriers to collaborative transition services.

Last, an accessible information channel regarding the transition process and services for students with disabilities should be developed. One of the most difficult challenges identified by the teachers to help their pupils in transition was to obtain adequate information regarding services and resources available, in particular, finding suitable adult service agencies for individual students. In addition, the teachers also required information about other resources, such as tax benefits, income assistance, advocacy groups, and social events in the community for adults with disabilities. The lack of information sources available for the teachers may explain the difficulties reported by families of youth with disabilities in Manitoba in obtaining information of adult services (Mactavish et al., 2004). A central bureau or site office with appropriate professionals knowledgeable in all related areas and available to provide consultation, would be a far superior resource for educators and transition teams to prepare for transition.

\section{Conclusion}

The interviews with the teachers in this study presented a rich and detailed description of the current transition practices in secondary education in Winnipeg. The interviews suggest that the attention and effort placed on transition services and the roles of the schools in accommodating transition have grown considerably in the past few years. Most of the teachers assumed the major responsibility for coordinating transition services for students with disabilities. Their efforts were devoted to developing and providing student/family-centered, functional, inclusive, and collaborative transition services, such as by transition planning meetings, instructions, and transition fairs. However, some barriers to providing effective transition services were raised, such as a lack of supports and resources for stakeholders, unclear delineation of responsibilities between teachers and social workers regarding certain transition services, delay of adult services for youth with disabilities, and the lack of information about available services and resources. In short, the infrastructure to support students with disabilities for successful transition to adult life appears to be fragile. The government, schools, and other support agencies need to examine and address these issues to improve the current practice of transition services.

Due to the limited number of participants, the results of this study cannot be widely generalized. Although circumstances may vary by individual students, schools, school divisions, and provinces or territories, the experiences and perspectives of the teachers of this study may provide other practitioners with an opportunity to examine their own practices and identify potential issues and challenges to consider for effective transition services for students with disabilities. The perspectives of students and/or families may not parallel those of their teachers. Therefore, further research with students, families, government workers, and adult services agencies is strongly recommended to obtain a balanced perspective of the transition services in Winnipeg. 


\section{References}

Anderson, A. G., \& Asselin, S. B. (1996). Factors affecting the school-to-community transition of students with disabilities. The Journal for Vocational Special Education, 18(2), 63-68.

Baer, R. (2005). Coordinating transition services. In R.W. Flexer, T. J. Simmons, P. Luft, \& R. M. Baer (Eds.), Transition planning for secondary students with disabilities (pp. 336-358). Upper Saddle River, NJ: Pearson Education, Inc.

Blanchett, W. J. (2001). Importance of teacher transition competencies as rated by special educators. Teacher Education and Special Education, 24(1), 3-12.

Bogdan, R., \& Biklen, S. (1998). Qualitative research for education: An introduction to theory and methods (3rd ed.). Toronto, ON: Allyn \& Bacon.

Brolin, D. E., \& Loyd, R. J. (2004). Career development and transition services: A functional life skills approach (4th ed.). Upper Saddle River, NJ: Pearson Education, Inc.

Canadian Association for Community Living. (2006). Adult learning, training and employment. Retrieved February 2, 2007, from http://www.cacl.ca/english/priorityresouces/altemployment/index.html

Council for Exceptional Children (2000). Transition-related planning, instruction, and service responsibilities for secondary special educators. Fact sheet. Retrieved January 15, 2007, from http:// www.eric.ed.gov/ERICDocs/data/ericdocs2sq1/content_storage_01/0000019b/80/16/38/09.pdf

Flexer, R. W., \& Baer, R. M. (2005). Life satisfaction and productive futures. In R. W. Flexer, T. J. Simmons, P. Luft, \& R. M. Baer (Eds.), Transition planning for secondary students with disabilities (pp. 2-19). Upper Saddle River, NJ: Pearson Education, Inc.

Flexer, R. W., Simmons, T. J., Luft, P., \& Baer, R. M. (2005). Transition planning for secondary students with disabilities. Upper Saddle River, NJ: Pearson Education, Inc.

Freeze, D. R. (1996). Promoting successful transitions for students with special needs: A handbook of best practices for the education of students with special needs in transition from school to work and adult life: An outcome of the TAPAR Project: Transition and progress for all in rural areas. Winnipeg, MB, Canada: Canadian Council for Exceptional Children.

Gallivan-Fenlon, A. (1994). Their senior year: Family and service provider perspectives on the transition from school to adult life for young adults with disabilities. Journal of the Association for Persons with Severe Handicaps, 19(1), 11-23.

Greene, G. (2003a). Best practices in transition. In G. Greene \& C. A. Kochhar-Bryant (Eds.), Pathways to successful transition for youth with disabilities (pp. 155-196). New Jersey: Pearson Education, Inc.

Greene, G. (2003b). The final phases of transition: Follow-up and evaluation. In G. Greene \& C. A. Kochhar-Bryant (Eds.), Pathways to successful transition for youth with disabilities (pp. 292-313). Upper Saddle River, NJ: Pearson Education, Inc.

Greene, G., \& Kochhar-Bryant, C. A. (Eds.). (2003). Pathways to successful transition for youth with disabilities. Upper Saddle River, NJ: Pearson Education, Inc.

Grigal, M. (2000). Preparation of personnel in secondary special education and transition service delivery for youth with low incidence (severe) disabilities. Final performance report. Retrieved January 20, 2007, from http://www.eric.ed.gov/contentdelivery/servlet/ERICServlet?accno=ED460560

Horrocks, C. (1991). Isolation and security: Transition process and outcomes for graduates with mental handicaps. BC Journal of Special Education, 15(2), 177-198.

Johnson, S., \& Wehman, P. (2001). Teaching for transition. In P. Wehman (Ed.), Life beyond the classroom: Transition strategies for young people with disabilities (3rd ed., pp. 145-170). Baltimore: Paul H. Brookes.

Kamens, M. W., Dolyniuk, C. A., \& Dinardo, P. (2003). Preparing teachers for the transition of students with disabilities through community-based instruction. Career Development for Exceptional Individuals, 26(1), 99-118. 
Knoll, J. A., \& Wheeler, C. B. (2005). My home and community: Developing supports for adult living. In R. W. Flexer, T. J. Simmons, P. Luft, \& R. M. Baer (Eds.), Transition planning for secondary students with disabilities (pp. 424-459). Upper Saddle River, NJ: Pearson Education, Inc.

Kochhar-Bryant (2003a). Coordinating systems and agencies for successful transition. In G. Greene \& C. A. Kochhar-Bryant (Eds.), Pathways to successful transition for youth with disabilities (pp. 108152). Upper Saddle River, NJ: Pearson Education, Inc.

Kochhar-Bryant (2003b). Implementing interagency agreements for transition. In G. Greene \& C. A. Kochhar-Bryant (Eds.), Pathways to successful transition for youth with disabilities (pp. 314-379). Upper Saddle River, NJ: Pearson Education, Inc.

Kochhar, C. A., West, L., \& Taymans, J. (2000). Successful inclusion: Practical strategies for a shared responsibility. Upper Saddle River, NJ: Merrill/Prentice Hall.

Luecking, R. G., \& Certo, N. J. (2002). Integrating service systems at the point of transition for youth with significant disabilities: A model that works. Information brief. MN: National Center on Secondary Education and Transition.

Mactavish, J., Lutfiyya, Z. M., Blais, C., Backstrom, O., Ferec-Legall, S., Forbes, J., et al. (2004). Perspectives in change: Issues in community support for adults with intellectual disabilities: Phase 1, final report. Winnipeg, MB: HLHP Research Institute, SCE Lifeworks, and Network South.

Manitoba Education, Youth, and Citizenship (1989). Transition planning process. An interdepartmental protocol of Manitoba Education, Youth, and Citizenship, Manitoba Family Services and Housing, and Manitoba Health. MB: Author.

Manitoba Education, Youth, and Citizenship (n.d.). Funding process. Retrieved February 4, 2008, from http://www.edu.gov.mb.ca/k12/specedu/funding/process.html

Morningstar, M. E., Turnbull, A. P., \& Turnbull, H. R. III. (1995). What do students with disabilities tell us about the importance of family involvement in the transition from school to adult life? Exceptional Children, 62, 249-160.

National Council on Disability. (2000). Transition and post-school outcomes for youth with disabilities: Closing the gaps to post-secondary education and employment. Washington, DC: Author.

Office of Special Education Programs, U.S. Department of Education (2008). Individuals with Disabilities Education Act 2004 (Part II). Retrieved May 28, 2008, from http://idea.ed.gov/explore/home.

Phelps, L. S., \& Maddy-Bernstein, C. (1992). Developing effective partnerships for special populations: The challenge of partnerships and alliances. The Journal for Vocational Special Needs Education, $14(2 \& 3), 33-36$.

Roessler, R. T. (1990). Factors affecting employment success and quality of life: A one year follow-up of students in special education. Career Development for Exceptional Individuals, 13(2), 95-107.

Stuart, C. H., \& Smith, S. W. (2002). Transition planning for students with severe disabilities: Policy implications for the classroom. Intervention in School and Clinic, 37(4), 234-236.

Wehman, P. (2001). Life beyond the classroom: Transition strategies for young people with disabilities (3rd ed.). Baltimore: Paul H. Brookes.

Wehmeyer, M. S., \& Palmer, S. B. (2003). Adult outcomes for students with cognitive disabilities threeyears after high school: The impact of self-determination. Education and Training in Developmental Disabilities, 38(2), 131-144.

\section{Author's Note}

Correspondence concerning this article should be addressed to Youn-Young Park, Department of Education, University of Manitoba, Winnipeg, MB, R3T 2N5.

E-mail: younyoungpark@hotmail.com.

I would like to thank Z. M. Lutfiyya, J. VanWallegham, and C. Artuso for their thoughtful comments which improved this manuscript. 


\section{Appendix \\ Interview Questions for Special Education/Resource Teachers}

I would like to ask you some questions about your experience with transition services and the transition process in your school.

1. Tell me about your work background.

\section{Planning and Implementation of Transition Services}

2. How does your school develop and implement transition services for students with disabilities?

\section{Student and Family Involvement in the Transition Process}

3. How do students get involved in the transition process?

4. How do families get involved in the transition process?

\section{Inter-personnel and Interagency Collaboration}

5. How do your school personnel collaborate with each other in providing students with disabilities with transition services?

6. How does your school collaborate with other agencies or government departments regarding transition services?

\section{Overall Transition Services}

7. What are barriers to an effective transition process?

8. Do you have any suggestions to improve your school's transition services?

9. Is there anything else you'd like to mention? 